\title{
COMO ESTE MUNDO SE TORNOU POSSÍVEL? DO CAPITALISMO ORGANIZADO À DESORDEM PRESENTE*
}

\author{
Reginaldo Carmello Corrêa de Moraes ${ }^{1 * *}$ (D
}

RESUMO: Reflexão sobre a desagregação da chamada Idade de Ouro do pósguerra, a emergência da globalização e suas implicaçôes para a constituição das identidades sociais e a formulaçáo das políticas públicas. Ao final, especulase sobre a erosão das bases sociais dos agrupamentos políticos reformistas. Um dos efeitos deletérios dessa dissonância pode ser até mesmo a derrocada do Estado de Bem-Estar Social e da própria democracia representativa.

Palavras-chave: globalização; políticas públicas; capitalismo.

\section{HOW HAS THIS WORLD BECOME POSSIBLE? FROM ORGANIZED CAPITALISM TO THE PRESENT DISORDER}

ABSTRACT: Thoughts on the breakdown of the so-called postwar Golden age, the emergence of globalization and its rise for the making of social identities and a declaration of public policies. In the end, it is specific about the erosion of the social bases of reformist political parties. One of the following goals is: dissonance can even be a concept of social welfare and representative democracy.

Keywords: globalization; public policies; capitalism.

\section{¿Cómo SE Hizo POSIBLE ESTE MUNDO? \\ DESDE EL CAPITALISMO ORGANIZADO AL DESORDEN ACTUAL}

RESUMEN: Reflexión acerca de la ruptura de la llamada Edad de oro de la posguerra, la aparición de la globalización y su ascenso a la identificación de identidades sociales y una declaración de votos públicos. Al final, se especula sobre la erosión de las bases sociales de las agrupaciones políticas reformistas. Uno de los objetivos es: la disonancia puede ser incluso un concepto de bienestar social y de la democracia.

Palabras clave: globalización; políticas públicas; capitalismo.

\footnotetext{
* O artigo é resultado de pesquisa apoiada pelo Conselho Nacional de Desenvolvimento Científico e Tecnológico (CNPq) por meio de bolsa de produtividade em pesquisa.

${ }^{1}$ Instituto de Filosofia e Ciências Humanas, Universidade Estadual de Campinas - Campinas (SP), Brasil.

** In memoriam.

DOI: 10.1590/ES0101-73302019221702
} 


\section{Introdução}

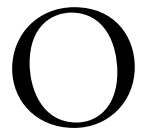

texto que segue é uma tentativa de reconstruir, de modo bastante seletivo e esquemático, uma trajetória complexa. Para isso, escolho uma abordagem modesta, mas que acredito útil. Trata-se de contrastar o momento atual com sua história, com a história da constituição de seus componentes mais visíveis. Como era o cenário passado, um pouco menos incerto, ainda que dependente de juízos? Quais as forças que parecem tê-lo modificado? Desse modo, creio, podemos entrever as tensões, contradiçóes do presente.

Minha tentativa de recuperaçáo do passado não vai muito mais longe do que um século, algo assim: começo do século XX. Naquele tempo, dizia Lenin (2010), em texto célebre: o Estado é, em resumo, uma coleção de prisōes e tribunais, um exército e uma polícia. Em uma palavra: repressão. Essa era a mensagem central do famoso Estado e Revoluçáo, publicado em 1917. De outro lado do espectro político, o liberal Max Weber (1993) dizia que o Estado se definia por deter o monopólio da coerção física legitimada. Isso aparece em sua notável conferência de 1918, A Política como Vocação, e é provavelmente a frase mais citada do sociólogo alemão. Em uma palavra: o Estado é repressão. Não nos perguntemos se havia algum tipo de intercâmbio entres esses autores, distantes ou mesmo opostos. Na famosa conferência, Weber menciona diretamente Trotsky, nesta direção: concorda com o dirigente soviético sobre a essência repressiva do aparato estatal. Mas não é necessário especular sobre esses diálogos e influências, basta pensar que Lenin, Trotsky e Weber tinham diante de si alguns simples fatos. O Estado capitalista, naquele momento, era basicamente aparato repressivo. Muito pouco além disso. Mesmo nos países avançados, o Estado recolhia parte pequena do produto interno bruto (PIB), menos de 10\%, a maior parte nas alfândegas e similares, e aplicava tais recursos precisamente na repressão e na guerra. Aliás, o imposto de renda progressivo, como política, é uma invenção do pós-Primeira Guerra, para dar conta de despesas deixadas pelo conflito bélico.

Devemos a Angus Maddison (1991) a compilação de preciosas informações de histórica econômica, e uma delas pode ser vista no Quadro 1.

Ao longo do século XX, o que vemos é uma enorme transformação desse Estado e do cenário político, com a expansão das políticas de governo e da carga tributária que as sustenta. Essa trajetória é uma parte da "grande transformação" a que se refere Karl Polanyi (2001), isto é, do movimento pelo qual instituiçóes políticas vão se construindo para domesticar o "moinho satânico do mercado". Um indicador dessa mutação é sugerido pelo Quadro 2. Nele podemos ver que os gastos tradicionais do Estado (fundamentalmente a defesa e a repressáo) constituem a parte menor do gasto, e as políticas sociais, aquilo que Maddison (1991) chama de "compromissos modernos", somam a maior parte do dispêndio estatal. 
Essas mudanças - que alteram a estrutura das sociedades e dos Estados nacionais - traduzem-se na experiência das classes trabalhadoras, de sua vida diária e, portanto, nos fatores que induzem a formação de comportamentos políticos. Ian Gough $(1979$, p. 2) sugere tais implicaçóes fazendo um simples paralelo entre o que era o welfare state inglês por volta de 1860 e o que ele tinha virado em 1970. O autor seleciona quatro eixos de políticas públicas. O primeiro, as políticas de manutenção ou distribuição de renda, era praticamente nulo em 1860, resumindo-se a políticas de socorro à pobreza extrema. Em comparação, em 1970, o Estado era responsável por um grande conjunto de programas: amparo a idosos e inválidos, pensōes e aposentadorias, auxílio-maternidade, seguro para acidentes de trabalho, seguro-desemprego, socorro a famílias em dificuldade e assim por diante. No segundo eixo, saúde, o contraste era igualmente visível - do nada em 1860 a uma política de socorro médico gratuito e universal um século depois. No terceiro eixo, a educação, praticamente resumida ao repasse de poucas verbas do parlamento para escolas religiosas, passou-se a um amplo sistema de educação elementar (dez anos), abrangente e gratuito. No quarto eixo, moradia, um novo mundo erguera-se: já em 1970, praticamente um quarto das moradias era providenciado pelo governo, a preços subsidiados, e o setor privado tinha aluguéis controlados. Assim, o gasto público com o que se podia chamar de políticas sociais passava de 1,5\% do PIB, em 1860, para 24\% em 1970.

Esses são apenas alguns flashes da mudança, mas, como dissemos, com base neles podemos fazer um exercício de imaginação sociológica: o que isso significava na experiência cotidiana da classe trabalhadora, na formação de seus sentimentos, de sua relação com o Estado e com a política? No movimento inverso, o que isso devia ao movimento constante de envolvimento desses segmentos sociais nos confrontos que superam os muros das fábricas e dos sindicatos? Mais uma vez, um quadro de Maddison (1991) sugere-nos essa visão² (Quadro 3).

\section{Quadro 1}

Gasto público total como porcentagem do produto interno bruto (PIB), 1913-1987

\begin{tabular}{|l|c|c|c|c|c|c|}
\hline & $\mathbf{1 9 1 3}$ & $\mathbf{1 9 2 9}$ & $\mathbf{1 9 3 8}$ & $\mathbf{1 9 5 0}$ & $\mathbf{1 9 7 3}$ & $\mathbf{1 9 8 7}$ \\
\hline França & 8,9 & 12,4 & 23,2 & 27,6 & 38,8 & 53,6 \\
\hline Alemanha & 17,7 & 30,6 & 42,4 & 30,4 & 42,0 & 47,3 \\
\hline Japão & 14,2 & 18,8 & 30,3 & 19,8 & 22,9 & 33,9 \\
\hline Países Baixos & 8,2 & 11,2 & 21,7 & 26,8 & 45,5 & 59,7 \\
\hline Reino Unido & 13,3 & 23,8 & 28,8 & 34,2 & 41,5 & 45,2 \\
\hline Estados Unidos & 8,0 & 10,0 & 19,8 & 21,4 & 31,1 & 37,0 \\
\hline Média & 11,7 & 17,8 & 27,7 & 26,7 & 37,0 & 46,0 \\
\hline
\end{tabular}

Fonte: Maddison, 1991, p. 62. 
O quadro é mais do que instigante. No espaço de um século, segmentos cada vez maiores da população desses países incorporaram-se ao processo eleitoral. As classes populares passaram a reivindicar a criação e a implementação de políticas públicas. Em sentido inverso, o aparato político viu-se obrigado a considerar tais demandas, mesmo quando apenas para traí-las.

Nessa grande marcha, encontramos, porém, um movimento gradual, cumulativo, um momento que talvez seja mais relevante, pela ruptura que evidenciou. Trata-se da Segunda Guerra Mundial. Esta dividiu o século em dois momen-

\section{Quadro 2}

Estrutura do gasto público como porcentagem do produto interno bruto (PIB), $1981^{1}$

\begin{tabular}{|l|c|c|c|c|c|c|}
\hline & França & Alemanha & Japáo & $\begin{array}{c}\text { Países } \\
\text { Baixos }\end{array}$ & $\begin{array}{c}\text { Reino } \\
\text { Unido }\end{array}$ & $\begin{array}{c}\text { Estados } \\
\text { Unidos }\end{array}$ \\
\hline Compromissos tradicionais & 3,8 & 2,9 & 0,9 & 3,3 & 5,0 & 4,7 \\
\hline Militares & 3,7 & 3,9 & 3,3 & 6.1 & 3,6 & 3,7 \\
\hline Civis & 2,2 & 2,2 & 3.6 & 5.4 & 5,0 & 2,7 \\
\hline Juros da dívida & 9,7 & 9,0 & 7,8 & 14.8 & 13,6 & 11,1 \\
\hline Total & \multicolumn{5}{|l|}{} \\
\hline Compromissos modernos* & 3,9 & 4,9 & 6,0 & 3,8 & 4,3 & 3,2 \\
\hline Econômicos & 5,9 & 5,2 & 4,9 & 7,0 & 5,4 & 5,7 \\
\hline Educaçáa & 6,4 & 6,8 & 4,7 & 6,6 & 5,0 & 3,7 \\
\hline Saúde & 3,7 & 2,3 & 2,9 & 5,0 & 2,2 & 0,8 \\
\hline Moradia & 11,9 & 12,6 & 4,7 & 12.9 & 7,4 & 6.7 \\
\hline Pensóes & 5,3 & 4.1 & 2.2 & 4.8 & 3,1 & 1.0 \\
\hline Outras transferências & 37,1 & 35,9 & 25,4 & 40,1 & 27.4 & 21,1 \\
\hline Total &
\end{tabular}

*Basicamente, infraestrutura.

Fonte: Maddison, 1991, p. 63.

\section{Quadro 3}

Eleitorado como percentual das pessoas adultas (20 anos ou mais)

\begin{tabular}{|l|c|c|c|c|c|}
\hline & $\mathbf{1 8 6 9 - 1 8 7 3}$ & $\mathbf{1 9 7 2 - 1 9 7 5}$ & & $\mathbf{1 8 6 9 - 1 8 7 3}$ & $\mathbf{1 9 7 2 - 1 9 7 5}$ \\
\hline Áustria & 10,6 & 98,0 & Noruega & 8,5 & 99,4 \\
\hline Bélgica & 3,7 & 94,3 & Suécia & 9,8 & 96,3 \\
\hline Dinamarca & 25,8 & 98,5 & Suíça & 38,7 & 83,5 \\
\hline Países Baixos & 5,0 & 98,0 & Reino Unido & 14,9 & 104,0 \\
\hline França & 42,0 & 87,5 & Itália & 3,5 & 99,4 \\
\hline Alemanha & 33,0 & 98,8 & Média & 17,8 & 96,2 \\
\hline
\end{tabular}

Fonte: Maddison, 1991, p. 61. 
tos bem distintos: surgiu uma nova potência hegemônica, elaborou-se um novo quadro institucional e emergiu um novo paradigma de pensamento político, por assim dizer (MORAES, 2006).

\section{Consenso keynesiano e economia mista}

Já se chamou o período do pós-guerra de Idade de Ouro do capitalismo contemporâneo - ou de "30 gloriosos do pós-guerra", a expressão difundida por Jean Fourastié (1975). Momento de reconstrução, de extraordinária acumulação de capital e relativo controle sobre as instabilidades desse modo de produção, esse período viu surgir um novo quadro institucional nos países centrais, o que iria constituir a chamada tríade (Europa e Estados Unidos e, depois, Japão).

O “capitalismo organizado" (LASH \& URRY, 1987) do pós-guerra tem duas dimensões importantes nos paises':

- O crescimento do tamanho do Estado, como produtor de bens e serviços, mas também como agente regulador das atividades socioeconômicas;

- Mudanças na natureza do Estado, na forma das instituições, com formas de governo relativamente estáveis e coesas.

O pós-guerra também reestruturou o espaço entre os Estados em vários sentidos. Por exemplo, estabeleceu novas relaçóes econômicas entre os Estados, por meio das regras criadas na famosa conferência de Bretton Woods, em 1944, e a moeda norte-americana como divisa internacional, com o sistema de paridade ouro-dólar. Além disso, foi inventada uma trinca poderosa para administrar o futuro global:

- Uma organização voltada para disciplinar o comércio entre fronteiras, a Organização Internacional do Comércio (OIC), logo enterrada e substituída por algo mais modesto, mas bem efetivo, o Acordo Geral sobre Tarifas e Comércio (GATT, na sigla inglesa) . O objetivo era regularizar (e estimular) o comércio internacional;

- Uma organizaçáo voltada para a gestáo do sistema monetário internacional, o Fundo Monetário Internacional (FMI).

- Um banco para a reconstrução, que ficou conhecido como Banco Mundial.

Essa trinca deveria, supostamente, regular um sistema de capitalismos nacionais. $\mathrm{O}$ acordo parecia prever relativa autonomia para os Estados nacionais, de modo que se protegessem contra movimentos de capitais e salvassem sua estabilidade interna. A frase de Keynes (1933), em um artigo ainda dos anos 1930, parece resumir essa utopia tornada projeto: 
Eu concordo, portanto, com aqueles que desejam reduzir e não ampliar o intercâmbio entre as naçóes. Idéias, conhecimento, ciência, hospitalidade, viagens - estas são as coisas que devem ser internacionais pela sua própria natureza. Mas deixemos que a produção dos bens seja caseira, sempre que possível, razoável e convenientemente. E, acima de tudo, deixemos que as finanças sejam principalmente nacionais (KEYNES, 1933).

Era o que a literatura também chamava de consenso keynesiano - a afirmação, como ideal, de uma economia capitalista em que o Estado manejava as grandes variáveis econômicas e, assim, moderava as crises inerentes ao sistema. Paul Samuelson (1972), no manual de economia mais difundido do planeta, resumia essa ideia com a expressão "economia mista”, aquela em que se preserva a propriedade privada dos meios de produção e as relaçóes de mercado, mas se admitem (e até se promove) forte intervenção e regulação estatal.

Para termos uma ideia das cercas de proteção em torno dos países, basta lembrar algumas das restriçôes vigentes em praticamente todos os países signatários do acordo do pós-guerra. Sáo restriçóes ao movimento de divisas e capitais por parte dos Estados, basicamente:

- $\quad$ O direito de limitar a posse, por seus cidadãos, de moeda estrangeira;

- Também o direito de limitar a atividade de suas instituiçóes financeiras no espaço internacional;

- $\quad \mathrm{O}$ direito de regular a atividade de instituições financeiras estrangeiras em seu território;

- Instrumentos para limitar a propriedade estrangeira de ativos locais (açóes, participação em sociedades, investimentos diretos).

Nesses 25 ou 30 gloriosos anos do pós-guerra, foi-se constituindo o que se chamou de tríade da riqueza e do poder: Estados Unidos, Europa e Japáo - a tríade do mundo ocidental, porque o mundo já se dividia entre o Leste Socialista e o Ocidente Capitalista. Constituiu-se, também, um andar inferior, o chamado terceiro mundo, os países subdesenvolvidos exportadores de matérias-primas. $\mathrm{O}$ mapa do mundo foi significativamente transformado, como se pode ver na Figura 1.

Essa imagem representa um processo: o fim da guerra resultou na descolonização, no nascimento de mais de uma centena de novos países, sobretudo na África e na Ásia. Esse terceiro mundo era o espaço de competição entre Ocidente e Oriente. De certo modo, pode-se dizer que a guerra acabava no primeiro mundo, mas as guerrilhas apenas começavam na periferia terceiro-mundista. Guerra Fria no mundo de cima, guerrilhas quentes no lado sul do planeta. 
De qualquer modo, sobretudo para os países centrais, a Idade de Ouro caracterizou-se por um cenário bem mais estável e coeso, ainda que com crises e conflitos. Nesse cenário, podemos destacar algumas características:

- Crescimento econômico rápido;

- Expansão dos Estados de bem-estar social;

- Estabilidade dos sistemas de representação, com alinhamentos partidários (e eleitorais) bastante claros;

- Estabilização nas relaçóes de trabalho, por meio de negociaçóes em escala nacional - organizaçóes patronais e de trabalhadores negociavam sob a égide do Estado;

- Estabilidade (ou previsibilidade) do sistema internacional. O mundo, basicamente organizado em dois polos, convivia com o empate da Guerra Fria.

Se o mundo era assim estabilizado pelas grandes potências no pós-guerra, se o sistema capitalista viu sua Idade de Ouro florescer, é preciso explicar por que esse mundo ruiu depois dos famosos "trinta gloriosos".

Houve nessa trajetória de desmanche um componente gradual e, digamos, natural, tanto quanto podem ser naturais os processos sociais. Eram, em grande medida, problemas resultantes do próprio sucesso do modelo - que crescia a ponto de não mais caber no enquadramento institucional que o propiciara.

\section{Figura 1}

A descolonização depois da Segunda Guerra Mundial: novos países independentes

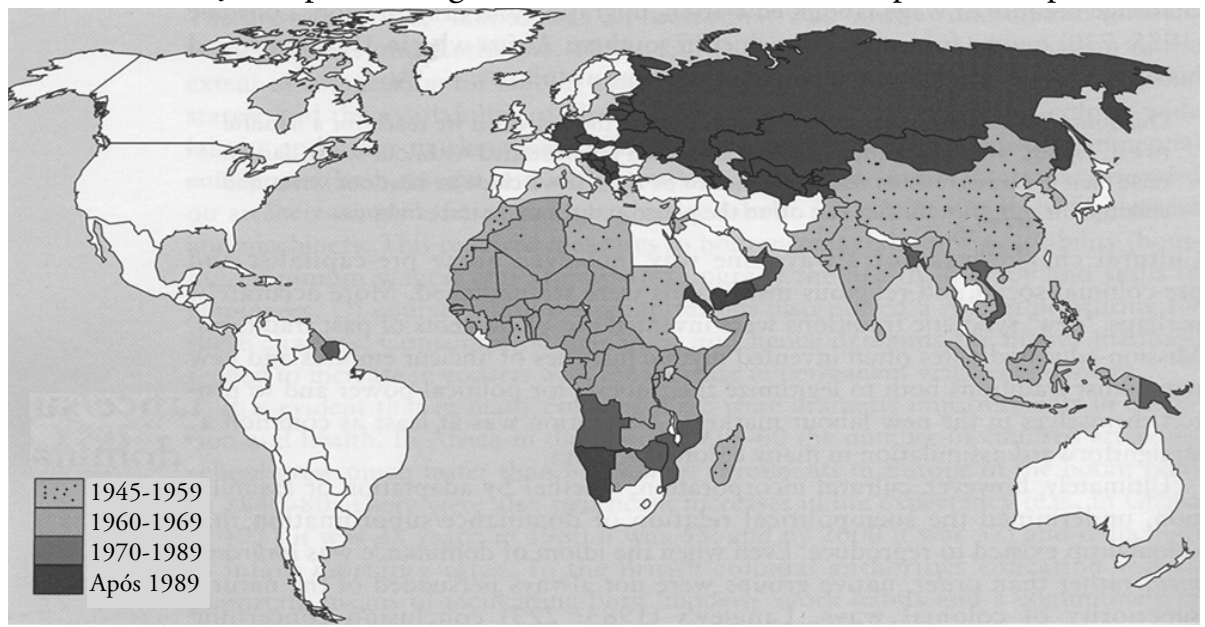

Fonte: Knox; Agnew; McCarthy, 2008, p. 25. 
Mas houve também momentos de ruptura - e que dependiam de escolhas políticas, de iniciativas. Vejamos alguns deles.

\section{Primavera capitalista depois da guerra}

Entre os sucessos do modelo, no pós-guerra, podemos registrar os seguintes:

- Crescimento do comércio internacional e redução das barreiras tarifárias. Cada vez mais os países (sobretudo ocidentais) produzem mais para exportar e consomem mais bens importados. A Figura 2, a seguir, ilustra o argumento.

- Crescimento dos investimentos diretos estrangeiros - implantação de filiais de manufaturas americanas e europeias, inclusive em países do terceiro mundo. Alguns deles entraram em um grupo que podemos chamar de semiperiferia industrializada. É o caso do Brasil, principal-

\section{Figura 2}

Crescimento do produto interno bruto (PIB) e das exportaçōes mundiais entre 1950 e 2000

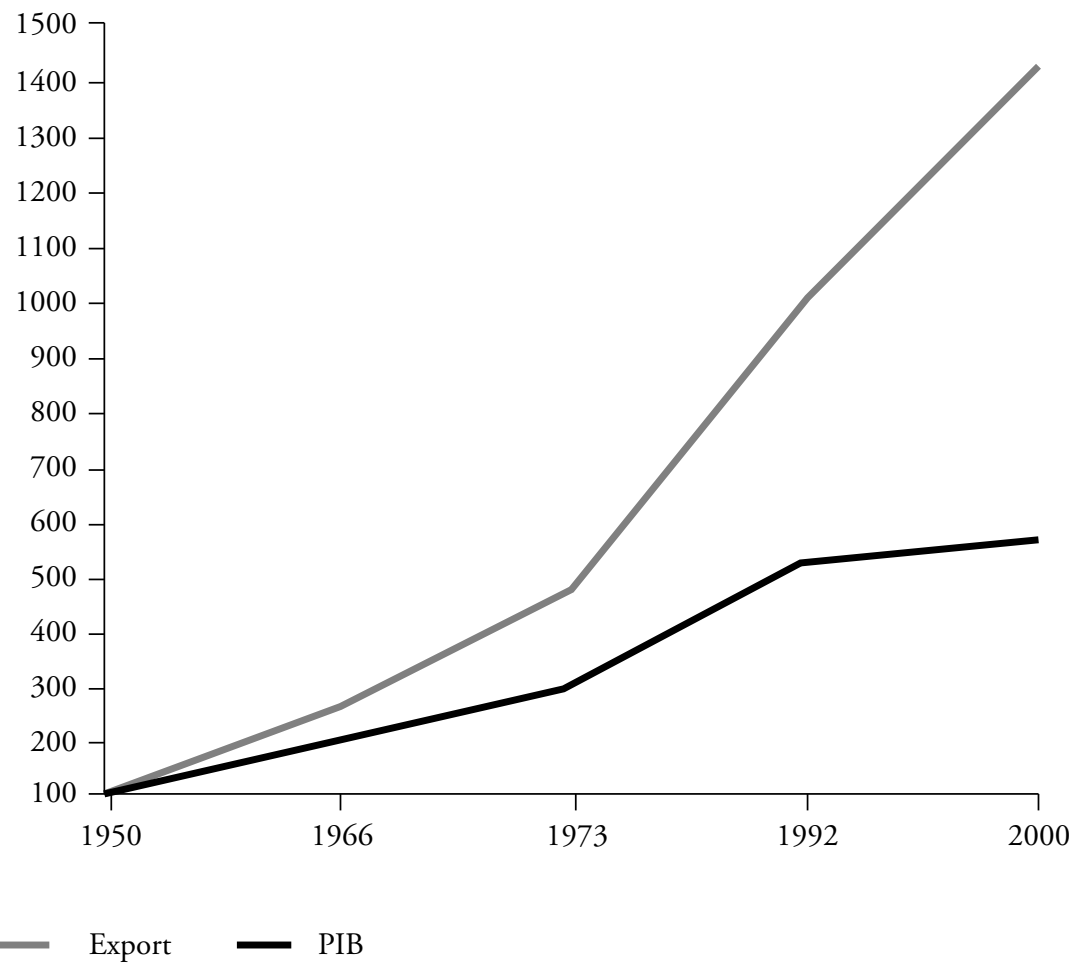

Fonte: Carroué; Collet; Ruiz, 2005, p. 71. 
mente depois de 1950. Esse movimento alterou o mapa anterior, aquele dos países do terceiro mundo. Uma parte da periferia descolou-se, conforme indica a Figura 3.

Uma parte significativa dessa transformação deve-se a um evento inédito na história do capitalismo. No começo do século XX, Lenin (2010) definiu o imperialismo como uma era em que o relevante era a exportaçáo de capitais, não a exportação de mercadorias. Mas é possível verificar que até o imediato pósSegunda Guerra a expansão dos capitais europeus e americanos fluía em direção a empreendimentos extrativos e infraestrutura auxiliar (estradas, portos, energia). Depois de 1945, houve uma alteração fundamental: a transnacionalização da manufatura, sobretudo da manufatura norte-americana. Com essa evolução, em meados dos anos 1960, a rede de filiais das manufatureiras americanas era, por assim dizer, a segunda economia industrial do mundo (MORAES, 2006).

Todavia, não foram apenas estes dois vetores que se desenvolveram no espaço global - comércio e indústria. Atrás dos dois, veio também a internacionalizaçáo gradual do sistema financeiro, preparando aquilo que, depois de 1980, viria a ser chamado de globalizaçãó .

A internacionalização da manufatura e de alguns investimentos diretos no setor extrativo (minérios, combustível) foi pressionando o sistema para a criação de instituiçõos financeiras mais flexíveis.

Figura 3

Hierarquia da riqueza e do poder

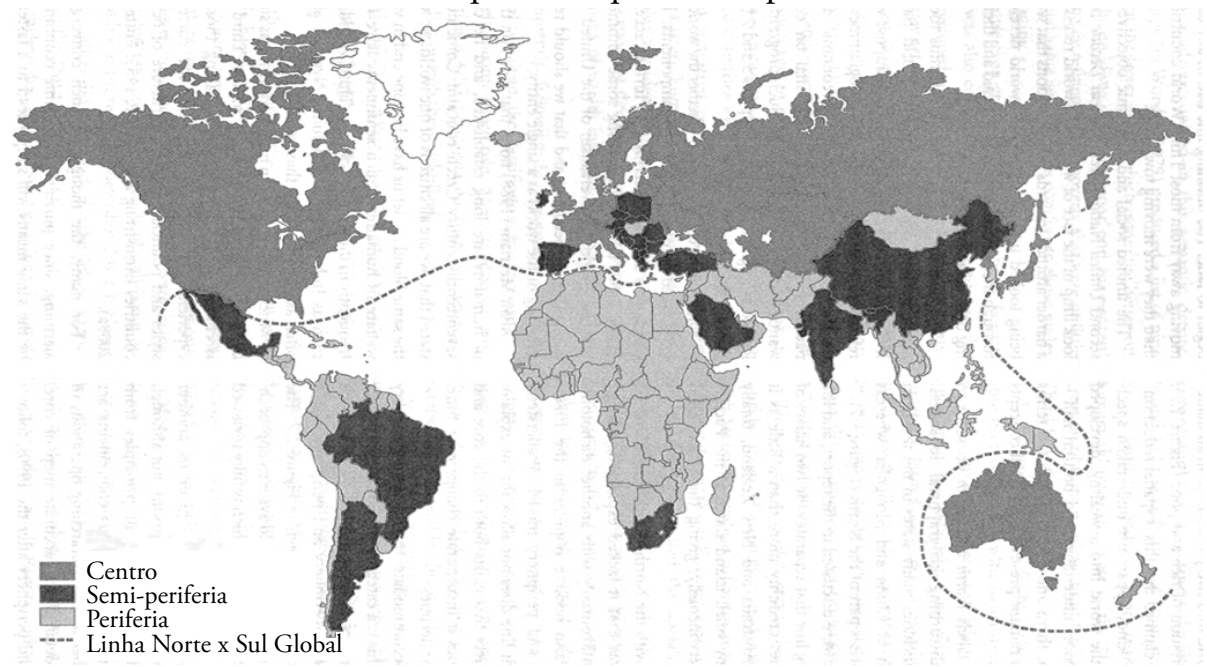

Fonte: Potter et al., 2008, p. 30. 
Recordemos que, em 1995, já em pleno vigor da famosa globalização, dois terços dos bens americanos vendidos no exterior eram efetivamente fabricados no exterior. Uma parte grande da produção industrial das firmas americanas (quase um quarto) era feita no exterior. Com o tempo, formou-se um novo modo de produzir (em cadeias) que mudou o próprio conceito de comércio - no fim do século XX, um terço do comércio mundial era, de fato, comércio intrafirma, isto é, trânsito de mercadorias (componentes, por exemplo) dentro da mesma firma, não apenas dentro do mesmo setor ${ }^{5}$.

Ora, as multinacionais, lideradas pelas americanas, operavam de modo muito singular. Isso incluía manufaturas e, também, as bilionárias empresas do minério e do petróleo. Elas geravam massas enormes de recursos - lucros, royalties, licenças - que precisavam ser processados pelo sistema financeiro e bancário e repatriados para seus titulares — os proprietários na matriz — ou reinvestidos. Isso acumulava uma enorme liquidez - dólares disponíveis - que era depositada em um sistema que operava na fronteira do sistema legal e regulado conforme estabelecido em Bretton Woods (BLOCK, 1980).

Esse é um dos fatores que originaram o famoso mercado paralelo dos eurodólares. Montanhas de recursos depositados em bancos europeus, mas em contas denominadas de dólares, e ávidos por investimentos novos, rápidos, lucrativos. Não por acaso, eles foram empurrados goela abaixo para as ditaduras africanas e sul-americanas, que queriam construir pirâmides do novo século. Contratos de dívidas a juros flutuantes, armadilhas com tempo previsto de disparo. Esse movimento híbrido - uma gambiarra no sistema Bretton Woods - mostrava como as finanças, especialmente, precisavam de uma nova armação institucional, uma desregulação.

É bom lembrar, rapidamente, que, apesar da manufatura espalhada pelo mundo, constituindo uma semiperiferia industrializada, a tríade (Estados Unidos, Europa Ocidental e Japão) conservava o controle do sistema. Os centros decisórios e de inovação, a manufatura de alta tecnologia, os serviços sofisticados continuavam no centro; apenas suas pontas menos determinantes migraram para os países do Sul do mundo.

Como dissemos, o mundo legal criado em 1944 estava ficando pequeno para o mundo ampliado pelos sucessos dos 30 gloriosos. De maneira especial, é possível dizer, começava o caminho para lançar o programa que podemos chamar de Finanças Sem Fronteiras.

É o que se implantou com o big bang dos anos 1980 - desencadeado por dois Estados centrais, as duas principais praças financeiras do globo. Margaret Thatcher iniciou o processo na Inglaterra, Reagan deslanchou-o nos Estados Unidos. O processo de liberalização e desregulamentação que criou o tsunami financeiro diário em que vivemos é um giro diário de operaçóes nos mercados internacionais e de valores que supera, faz tempo, a escala do trilhão de dólares. 
O sistema bancário e financeiro deixava de ser nacional - mesmo em sistemas muito regulados, como o americano - e funcionava praticamente 24 horas por dia. As bolsas não dormiam. Não por acaso, os yuppies desse segmento viviam à base de estimulantes exóticos, mas essa evolução gradual e seu momento de big bang (anos 1980) tiveram dois momentos relevantes, dois pontos críticos, ainda nos anos 1970 .

Um deles, bem no começo, em 1971, foi quando o governo americano simplesmente enterrou uma regra estabilizadora fundamental de Bretton Woods, o lastro ouro. Até ali, o banco central americano (Federal Reserve Board - FED) comprometia-se a manter um estoque de ouro suficiente para lastrear a moeda impressa, o dólar. Comprometia-se a entregar ao portador de uma cédula de um dólar a quantidade de um grama de ouro. Era essa aproximadamente a paridade fixa do dólar, a divisa internacional, a referência dos contratos do mundo. As outras moedas tinham também uma paridade fixa com o dólar - podiam variar muito pouco (perto de 1\%) de tempos em tempos. Em 1971, Nixon disse: "Isso acabou".

A decisão americana teria efeitos brutais. O dólar e as outras moedas começaram a flutuar. Não de vez em quando; a cada ano, digamos. Variavam muitas vezes durante o dia! Assim, a especulação com a compra de moedas — uma bolha no oceano, até então - transformava-se em um negócio tentador, um oceano inteiro. E mais: não apenas a compra de pacotes de moedas, mas a compra de contratos de futuros. Assim, quando comprava uma opção de compra de café, trigo ou óleo, não especulava apenas o preço dessas commodities na bolsa de mercado futuro. Eu especulava o valor da moeda em que eram expressos os contratos. O chamado mercado de câmbio deu um salto que pôde ser visto, em certa escala, na Figura 4. Ela indica não crescimento, mas mudança de qualidade, uma verdadeira mutação do ambiente econômico.

A especulação, que era bolha no oceano, virou o próprio oceano. Com isso, as compras de futuros - que eram estímulo e garantia para produção, uma espécie de crédito e seguro - viraram um elemento de instabilidade, de desestímulo ao esforço produtivo e estímulo à especulação. Empresas inteiras dedicavam cada vez mais dinheiro e inteligência para especular em vez de produzir e inovar.

Haveria outro evento, ainda nos anos 1970, que teria efeitos brutais principalmente para aqueles países do terceiro mundo que tinham feito dívidas, aproveitando a liquidez maravilhosa dos eurodólares. Em 1979, o governo americano decidiu triplicar o valor da taxa de juro de seus empréstimos, o que multiplicava a taxa vigorante nos mercados de Nova York e Londres. Ora, as ditaduras endividadas (como a brasileira) tinham contraído empréstimos a juros flutuantes, a taxa vigorante nessas praças financeiras. A partir daí, em vez de governar suas dívidas, os países da periferia começaram a ser governados pela dívida, isto é, monitorados pelos bancos, que se permitiam dizer até a cor da bandeira. 
O mercado de divisas explodiu. Os preços de commodities, moedas, ações variavam agora diversas vezes ao dia. $\mathrm{O}$ mundo mudava de cara várias vezes ao dia. E a instabilidade daí resultante se espalhava para todos os aspectos da vida social. Do preço do pão à tarifa dos ônibus ou à nota de crédito de um país.

A instabilidade global ainda seria ajudada por outros fenômenos, como a concorrência internacional acirrada e os choques do petróleo, que praticamente afundaram as contas externas e, em certos momentos, criaram um pânico até nos países centrais.

Já no meio dos anos 1970, a Comissão Trilateral, o fórum da tríade, decretou o fim de uma era: as democracias eram ingovernáveis, as demandas sociais ameaçavam a estabilidade capitalista; era necessário limitar os sistemas políticos, torná-los menos vulneráveis à vontade popular (CROZIER; HUNTINGTON; WATANUKI, 1975).

\section{Figura 4}

Crescimento do mercado de câmbio: volume médio das transações diárias

Em bilhōes de dólares correntes

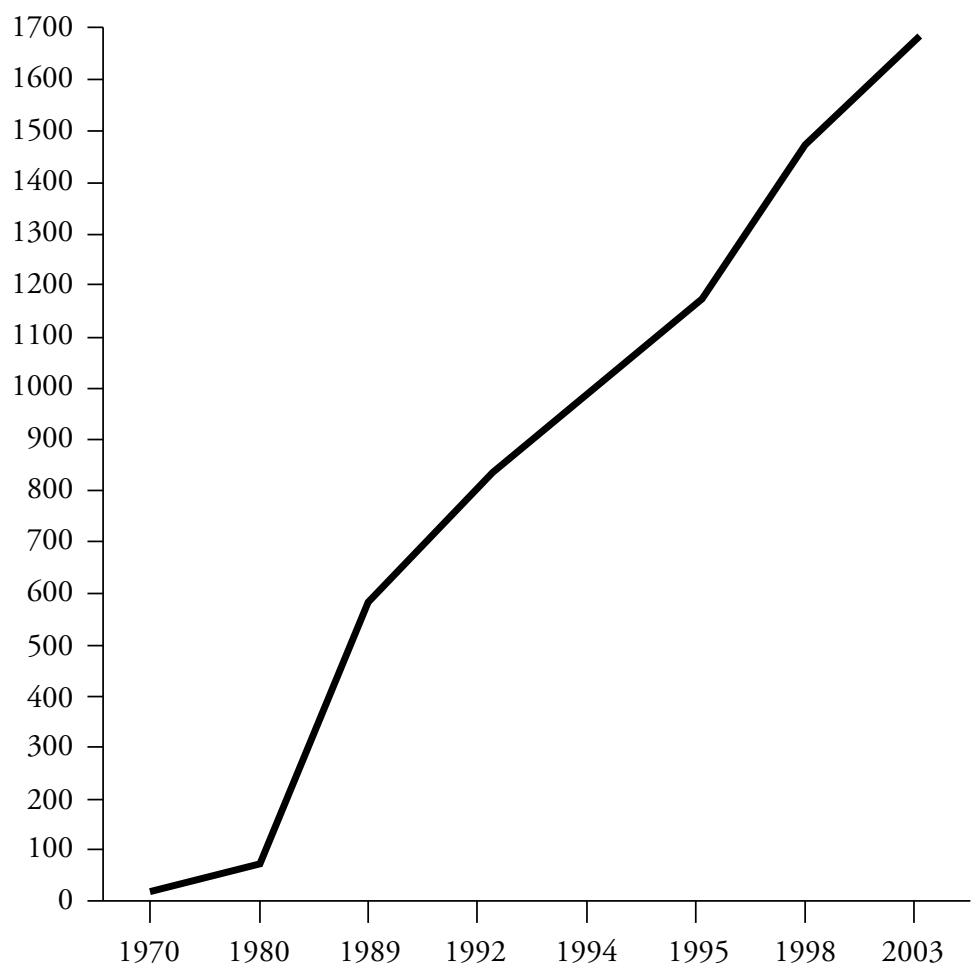

Fonte: Carroué; Collet; Ruiz, 2005, p. 75. 


\section{Capitalismo fim de século}

Nos anos 1980 ficavam à vista os três mundos da reforma, os alvos da nova estratégia imperialista. No primeiro mundo, a começar pelos Estados Unidos e pela Inglaterra, o big bang financeiro de Thatcher e Reagan. O desmantelamento do segundo mundo (as economias planificadas do leste europeu) seria estimulado por diversas vias, e o terceiro mundo seria guiado pelo cabresto da dívida e dos planos de ajuste estrutural recomendados pelo FMI, pelo Banco Mundial e pelos bancos privados credores.

Desse modo, diante daquele quadro de crescimento econômico, estabilidade política relativa, alinhamentos eleitorais previsíveis e negociações, erguia-se um novo cenário mundial, aquele em que, em certa medida, ainda nos movemos. Com isso, penso ter realizado o que prometi no começo desta conversa. Escrutinar as forças que deram origem ao cenário atual como uma forma de vislumbrar suas principais características, seus pontos de tensão, seus padróes de mudança no passado e, quem sabe, no futuro próximo.

Talvez seja útil, então, destacar alguns desses traços, lembrando que são quase o simétrico daquele que visualizamos agora pouco, o cenário dos 30 gloriosos.

Esse cenário novo teria os seguintes eixos:

- Mudanças rápidas na organização do sistema produtivo, mas crescimento econômico precário e ciclotímico. Abria-se uma era de incerteza ampliada, de insegurança, uma era do medo generalizado;

- Ampliação das desigualdades sem precedentes na história do capitalismo, talvez comparável apenas ao seu momento de formação;

- $\quad$ Redução do Estado que se manifestava, sobretudo, na pressão sobre políticas públicas. Estas refletiam conquistas seculares dos movimentos populares (saúde, educação, previdência etc.);

- Mundo do trabalho pulverizado, fragmentado e desnorteado, graças à combinaçáo perversa de reformas econômicas (macro e micro) e às notáveis inovaçôes tecnológicas, com a automação e o uso da inteligência artificial;

- Crescente movimento de restriçóes à democracia, mesmo à frágil democracia representativa que foi bandeira da reconstrução do pós-guerra.

De fato, esses eixos são mais do que vetores independentes, são parte de uma espécie de síndrome, em que os fatores causais se cruzavam e interferiam entre si. De maneira especial, para os leitores de Educação \& Sociedade, vale destacar o enorme impacto que todos eles tiveram para transformar radicalmente as condiçôes de formulação e implementação de políticas públicas de educação. 


\section{Enquanto isso, nos andares de baixo}

Recapitulemos. Mencionei o cenário do começo do século e contrastei-o com o do fim do século, do Estado quase mínimo para o Estado desenvolvido. Visitamos uma sequência de cenários, ou situaçóes, para entender melhor como se constituiu o cenário atual. Esse é o grande cenário mundial - aquele das grandes potências e dos grandes movimentos econômicos e políticos. As grandes tendências, as mais visíveis, talvez. Mas, para entender o momento presente e, principalmente, os terremotos políticos do momento, faz falta observar os níveis inferiores da geologia, os subterrâneos da sociedade ocidental.

Essa observação, que passo a comentar agora, é essencial para entendermos esse novo cenário - o cenário que talvez possamos chamar de nova era de incerteza e insegurança. Incerteza e insegurança que se manifestam de modo claro, agressivo e mesmo violento na Europa, nos Estados Unidos e, também, no Brasil, assombrando a sobrevivência não apenas dos Estados de bem-estar, mas a própria democracia e o próprio Estado democrático de direito.

No livro já mencionado, Polanyi (2001) aponta que a história do capitalismo foi marcada por um duplo movimento. De um lado, o movimento do moinho satânico do mercado, um movimento que deixado a si mesmo era predatório, destruiria a humanidade e mesmo o planeta. De outro, o movimento de autodefesa da sociedade, por vezes forjando alianças inesperadas, entre aristocratas e donos de terra e movimentos de trabalhadores, por exemplo. Tratava-se da tentativa de regular, civilizar o moinho do mercado.

$\mathrm{Na}$ análise do autor, eu destaco um elemento. É o efeito civilizador dos movimentos "de baixo", a resistência popular que refreia os efeitos mais deletérios do moinho satânico do mercado. Foi essa resistência que conquistou políticas para moderar as contradiçóes e os conflitos, as desigualdades, tornando viável algum grau de coesão e de estabilidade política. A conquista das políticas sociais, das regulaçóes econômicas, da moderação do capital foi obra de sucessivas lutas de sindicatos, movimentos sociais, partidos reformistas.

Em certo sentido, foi esse movimento - que podemos chamar de esquerda social - que forçou a edificação de um Estado de bem-estar social e, com isso, de estabilidade e coesão social e estabilidade política indispensável para a sobrevivência da democracia e do Estado de direito.

Por isso, aquilo que chamamos de esquerda social - e de esquerda política - é um alicerce fundamental e vanguarda do Estado de bem-estar e do próprio Estado democrático e dos direitos civis. A questão que surge é esta: o que acontecerá ao welfare state e à própria democracia se essa força civilizatória enfraquecer? 
Porque parece que é este o cenário que vemos cristalizar-se nas últimas quatro décadas: a erosão da base social da esquerda política. Isso pode ser o prenúncio de uma tragédia. A base social dos partidos de esquerda - comunistas ou reformistas, socialistas, trabalhistas — foi desde o começo o proletariado industrial, ou melhor, a classe operária concentrada em grandes empresas. Desde as usinas públicas até as fábricas privadas. A frase de Lenin é conhecida: o capital concentra para explorar, e essa concentração torna-se a base da escola de política do proletariado.

A evolução do capitalismo das últimas décadas — com a automação, as reformas liberais, a reengenharia das empresas - conduziu à redução e fragmentação da classe trabalhadora e à pulverização política das classes populares. Isso enfraqueceu seus organismos de luta e formação de ideologia, os movimentos e sindicatos que são (ou eram) escolas políticas de massa. Essa nova condição enfraqueceu os partidos reformistas de vários matizes - comunistas, socialistas, socialdemocratas, trabalhistas, ou democrata-cristãos reformadores.

Nos países avançados, tanto quanto na semiperiferia industrializada, um conjunto de reformas macroeconômicas foi se consolidando nas últimas décadas, deixando sociedades à mercê de políticas de austeridade que produzem desespero. As reformas ajudaram a produzir essa fragmentação e essa dissolução de identidades sociais vinculadas à solidariedade e aos compartilhamentos coletivos. Privatizando serviços públicos, desregulamentando as relaçóes econômicas, alterando radicalmente a gestão do setor público, essas reformas afetaram radicalmente o meio em que vivemos, o modo como sobrevivemos, até mesmo a nossa relação com os bens e serviços públicos.

Somemos a todos esses fatores o avanço da automação e do uso da inteligência artificial na modelagem de todas as atividades sociais — da produção fabril à organização dos serviços públicos ou privados.

Assim, dois mundos são fragmentados: o mundo do trabalho e o espaço da reprodução da força de trabalho. As políticas públicas e sociais que haviam sido impostas ao capital tinham feito com que muitos bens essenciais mudassem de forma - passavam da compra e venda (compra no mercado) para a oferta via políticas públicas, para o universo do consumo coletivo (educação, saúde, moradia, transporte etc.). O desmantelamento do Estado de bem-estar e das políticas públicas inverteu o quadro; tratava-se de uma revanche do capital. Voltava-se ao quadro da compra e venda desses serviços, que deixavam de ser direitos de cidadão e passavam a ser bens comercializados. Vivemos assim, no cotidiano, uma relação de mercado generalizada com educação, saúde, transporte, água, vida.

Esse recuo abriu caminho para um fenômeno recente de enorme perigo, a migração dos contingentes populares para dois comportamentos políticos perigosos. Um deles é o apoio a candidatos e partidos de ultradireita. O outro, uma 
enorme abstenção política, o alheamento, quase tão perigoso quanto o primeiro. Em praticamente todas as eleiçóes dos últimos 40 anos, em quase todos os países, a abstenção tem crescido - e, sobretudo, precisamente no eleitorado potencialmente próximo da esquerda.

Ao lado dos fatores objetivos, isto é, das mudanças nas condiçóes de vida e na reprodução da força de trabalho, existe o que se pode chamar de fator subjetivo. Os fatores objetivos criam as condições de emergência de novas correntes ideológicas e políticas, mas não o sucesso dessas correntes. O sucesso depende do empreendimento das organizaçóes ideológicas capitalistas - da mídia e das Igrejas, por exemplo, dos aparatos ideológicos de reprodução do mando e da submissão. A mídia cria um quadro de sentimentos e de percepçóes, de valores, pelo canal virtual, a tela. O culto semanal (e as atividades outras) cria o espaço presencial de reafirmação e cimentação desses valores e orientações.

Concluo sintetizando o argumento central desta seção do artigo. A reforma do capitalismo - aquilo que o tornou suportável e garantiu sua sobrevivência minimamente civilizada - tinha bases socioeconômicas definidas e correntes políticas que delas emanavam, aquilo que denominei de "bases sociais da esquerda política”. Elas eram, por assim dizer, a garantia dos direitos sociais e civis que se construíram nos Estados contemporâneos, com diferentes graus de maturação. Nas últimas décadas, temos presenciado uma relativa erosão dessas bases e o enfraquecimento dos partidos reformistas. A era da fragmentação, do absenteísmo, da desesperança e do medo pode nos levar a um terrível pesadelo. As políticas públicas têm sido o alvo e a vítima perfeita para o início das ofensivas reacionárias que florescem nessas circunstâncias. Talvez esse seja o cenário mundial com o qual mais tenhamos de nos preocupar no momento.

\section{Notas}

1. De passagem, quase fatal comparar com a realidade brasileira. No orçamento da União, a cada ano, os gastos com o pagamento da dívida, o welfare dos bancos e rentistas, são várias e várias vezes o gasto com educação e saúde somados.

2. Maddison (1991) monta esse quadro condensando os dados reunidos pela equipe de Peter Flora. O trabalho de Flora e de seus parceiros é uma preciosa compilação dessas mudanças, algo que não podemos nem pretendemos explorar nas dimensóes deste artigo (FLORA et al., 1983).

3. Esse novo desenho dos Estados nacionais recebeu diversos tratamentos e diferentes nomes, além do "capitalismo organizado" de Lash e Urry (1987): economia mista (SAMUELSON, 1972), neocapitalismo (MANDEL, 1969), embedded liberalism (RUGGIE, 1991).

4. Uma síntese dessas três faces ou fases da globalização econômica pode ser encontrada nos capítulos 5, 6 e 8 do livro de Robert Gilpin (2002). 
5. Essa é uma descrição sumária de um processo muito complexo. Para uma visão geral da nova divisão do trabalho resultante da propagação das multinacionais, ver: capítuo 1 de Froebel, Heinrichs e Kreye (1980). Para o momento posterior, de subcontrataçáo generalizada dentro e fora do país (offshore), ver: Peck (2017). Para a teoria das cadeias produtivas, ver os ensaios reunidos em Gereffi e Korzniewicz (1994).

\section{Referências}

BLOCK, F. Los Orígenes del Desorden Económico Internacional. México: Fondo de Cultura Económica, 1980.

CARROUÉ, L.; COLLET, O.; RUIZ, C. La Mondialisation: Génese, acteurs et enjeux. Paris: Breal, 2005a.

CARROUÉ, L.; COLlET, O.; RUIZ, C. Les Mutations de l'Économie Mondiale: du début du XXe. Siècle aux Annés 1970. Paris: Breal, 2005b.

CROZIER, M.; HUNTINGTON, S.; WATANUKI, J. The crisis of democracy. Nova York: Nova York University Press, 1975.

FLORA, P. et al. State, Economy, and Society in Western Europe 1815-1975. Londres: MacMillan Press, 1983. v. 1.

FOURASTIÉ, Jean. Les trente glorieuses ou la révolution invisible de 1946 a 1975. Paris: Fayard, 1975.

FROEBEL, F; HEINRICHS, J.; KREYE, O. The New International Division of Labour. Cambridge: Cambridge University Press, 1980.

GEREFFI, G.; KORZNIEWICZ, M. (orgs.). Commodity Chains and Global Capitalism. Praeger: Westport Connecticut, 1994.

GILPIN, R. A Economia Política das Relaçóes Internacionais. Brasília: Editora $\mathrm{UnB}, 2002$.

GOUGH, I. The political economy of the welfare state. Londres e Basingstoke: MacMillan Press, 1979.

KEYNES, J. M. National Self-Sufficiency. The Yale Review, v. 22, n. 4, p. 755-769, jun. 1933.

KNOX, P.; AGNEW, J.; MCCARTHY, L. The Geography of the World Economy. Londres: Hodder, 2008.

LASH, S.; URRY, J. The End of Organized Capitalism. Cambridge: Polity Press, 1987.

LENIN, V. O Estado e a Revoluçáo: o que ensina o marxismo sobre o Estado e o papel do proletariado na revolução. Sáo Paulo: Expressão Popular, 2010.

MADDISON, A. Historia del Desarrollo Capitalista. Sus Fuerzas Dinámicas. Barcelona: Ariel, 1991. 
MANDEL, E. Ensayos sobre el neocapitalismo. México: Era, 1969.

MORAES, Reginaldo. Estado, desenvolvimento e globalização. São Paulo: Editora da UNESP, 2006.

PECK, J. Offshore: Exploring the Worlds of Global Outsourcing. Oxford: Oxford University Press, 2017.

POLANYI, M. A Grande Transformação: as origens políticas e econômicas de nosso tempo. Lisboa: Ediçóes 70, 2001.

POTTER, R. et al. Geographies of Development. Harlow: Pearson, 2008.

RUGGIE, J. G. Embedded Liberalism Revisited: Institutions and Progress in International Economic Relations. In: ADLER, E.; CRAWFORD, B. (orgs.). Progress in Postwar International Relations. Columbia: Columbia University Press, 1991.

SAMUELSON, P. Introduçáo à Análise Econômica. São Paulo: Agir, 1972.

STENGERS, I. (org.). D’une science à l'autre: Des concepts nomades. Paris: Seuil, 1987. WEBER, M. A política como vocação. In: WEBER, M. Ciência e Política. Sáo Paulo: Cultrix, 1993.

\section{SOBRE O AUTOR}

Reginaldo Carmello Corrêa de Moraes é professor titular aposentado do Departamento de Ciência Política da Universidade Estadual de Campinas (Unicamp). Pesquisador do Instituto Nacional de Ciência e Tecnologia para Estudos sobre Estados Unidos. Autor, entre outros, de Educação superior nos Estados Unidos: história e estrutura (Editora da Unesp, 2015).

Recebido em 24 de março de 2019.

Aceito em 24 de julho de 2019. 